\title{
Maximal supine exercise haemodynamics after open heart surgery for Fallot's tetralogy
}

\author{
GORDON R. CUMMING
}

From the Department of Pediatrics, Health Sciences Children's Centre and The University of Manitoba, Winnipeg, Manitoba, Canada

SUMMARY Maximal supine exercise studies at the time of heart catheterisation were performed one to five years after open heart surgery for Fallot's tetralogy on 29 subjects 6 to 16 years of age. During exercise right ventricular systolic pressure exceeded $50 \mathrm{mmHg}$ in all but 2 subjects, and end-diastolic pressure increased to over $15 \mathrm{mmHg}$ in 10 subjects. Pulmonary artery peak systolic pressure was abnormal in 5 patients. Maximal exercise cardiac index was below the normal range in only 2 subjects, but below the mean for normals in 80 per cent of the patients. Only 3 patients had clinical exercise performances below the 3rd centile of normal subjects using a maximal upright bicycle exercise test, and only 1 subject was below the normal range for endurance time on the Bruce treadmill test. The patients in this series performed better than those in other series, possibly because of their younger age at operation, the use of a large control series of normal subjects taken from a clinic population, the willingness of the patients to work to near exhaustion, and previous encouragement of the patients to become normally active children.

There are several published reports of haemodynamic studies after open heart surgery in patients with Fallot's tetralogy, and some of these include exercise data (Gotsman, 1966; Shah and Kidd, 1966; Bristow et al., 1970; Epstein et al., 1973; Bjarke, 1975; Mocellin et al., 1975, 1976). The following report differs from these others in one or more ways: studies were made during exercise on a large number of subjects including those with and without various residual defects; measurements were made during maximal exercise; haemodynamic measurements included intracardiac pressures, arterial and mixed venous blood gas tensions, and cardiac output (by indicator dilution method), during submaximal and maximal exercise in the supine position. Clinical exercise testing used both maximal treadmill and bicycle exercise. The subjects were younger than those in other series and comparative data were available for a large series of normal children studied in the same manner.

\section{Subjects}

The patients studied were 29 children who had had open heart operations at ages ranging from 5 to 14 years (mean $8 \cdot 2$ ). All but 2 were cyanotic at the time of operation. Of the $29(34 \%), 10$ had had a

Received for publication 20 February 1978 previous shunt operation. An outflow tract patch had been inserted in 11 of the 29 patients (38\%), and in 7 this extended to the pulmonary artery bifurcation. The catheterisation studies were carried out 1 to 5 years after operation (mean age 11.3 years, range 6 to 16). The exercise studies were performed at the time of diagnostic postoperative haemodynamic assessment.

The patients were divided into 5 subgroups: (1) those in the 'repaired' group with a closed ventricular septal defect and a peak gradient from right ventricle to pulmonary artery of $20 \mathrm{mmHg}$ or less (11 patients); (2) those with a closed ventricular septal defect but a peak gradient of over $20 \mathrm{mmHg}$ (7 patients);(3) those with a small residual ventricular septal defect and pulmonary blood flow 1.25 times systemic flow or less (4 patients); (4) those with a 'poor repair' with a large ventricular septal defect and also an outflow gradient of over $20 \mathrm{mmHg}$ (5 patients); and (5) 2 patients with complete atrioventricular block, both with a permanent pacemaker set at 80 beats/minute, but otherwise a good surgical result.

\section{Methods}

The haemodynamic studies were carried out after an overnight fast 45 minutes after diazepam $5 \mathrm{mg}$ 
or pethidine $25 \mathrm{mg}$. Catheters were introduced percutaneously into a cubital or femoral vein, and the brachial artery was cannulated with a Cournand needle. After the exercise studies most subjects also had right and left ventriculograms. Control measurements were obtained 5 minutes after the subject's feet had been placed on and strapped to the ergometer pedals. A calibrated Elema electric ergometer was used with pedalling rates of $60 \mathrm{rpm}$ for submaximal exercise and 70 to $75 \mathrm{rpm}$ for maximal exercise. Subjects exercised for 3 minutes at about $5 \mathrm{kpm} / \mathrm{min}$ per $\mathrm{kg}$ body weight, rested 3 minutes, then exercised for 3 minutes at 8 to $12 \mathrm{kpm} / \mathrm{min}$ per $\mathrm{kg}$, rested again for 5 to 10 minutes, and then exercised at 15 to $25 \mathrm{kpm} / \mathrm{min}$ per $\mathrm{kg}$ until they could no longer sustain the pedalling rate. The final work load (chosen on the basis of a clinical exercise test and the response to the previous loads) usually exhausted the subjects in 90 to 180 seconds. Oxygen uptake was not measured but the submaximal loads would have required about 14 and $25 \mathrm{ml} / \mathrm{min}$ per $\mathrm{kg}$ of oxygen, and the maximal loads if done aerobically 32 to $55 \mathrm{ml} / \mathrm{min}$ per $\mathrm{kg}$ of oxygen. Five of the 29 subjects did not exercise at a maximal work load as they were studied before maximal exercise testing was used routinely in the catheterisation laboratory.

During exercise pulmonary and brachial artery pressures were recorded using a Statham P23Db transducer, and immediately after the maximal exercise the catheter was withdrawn from the pulmonary artery to the right ventricle. Cardiac output was measured using indocyanine green dye and a Waters densitometer, and a dynamic calibration method (Shinebourne et al., 1967). For the few patients with significant left-to-right shunts, pulmonary blood flow was calculated from the indicator dilution curves using the forward triangle method (Hetzel et al., 1958), the left-to-right shunt was estimated using the method of Carter et al. (1960), and systemic output was derived from these two measurements. During the third minute at each exercise level, blood was withdrawn from the pulmonary and brachial arteries for $\mathrm{Po}_{2}$ and $p \mathrm{H}$ determinations. Percentage oxygen saturation was derived using the standard oxyhaemoglobin dissociation curve.

Clinical exercise testing was carried out on the upright bicycle ergometer and on the treadmill in a clinical laboratory. On the upright bicycle ergometer, the subjects exercised at 5 to $8 \mathrm{kpm} / \mathrm{min}$ per $\mathrm{kg}$ for 6 minutes, and at 9 to $13 \mathrm{kpm} / \mathrm{min}$ per $\mathrm{kg}$ for 6 minutes, after which the work load was increased by $100 \mathrm{kpm} / \mathrm{min}$ each minute until exhaustion occurred. Maximal work was expressed as $\mathrm{kpm} / \mathrm{min}$ per $\mathrm{kg}$ and compared with centiles for normal children established for this laboratory (Cumming, 1977a). Subjects also performed the Bruce treadmill test and the maximal work times were compared with $\stackrel{\vec{\rho}}{\rightarrow}$ centiles for normal children established for this laboratory (Cumming et al., 1978). Normal centile values for both treadmill and bicycle exercise were established from exercise tests in over 500 children who did not have heart disease and who were seen in a cardiac clinic over a 10-year period.

\section{Results}

The haemodynamic results are shown in Fig. 1 to 8 , with shaded areas to show the normal range (mean $\vec{A}$ \pm 2 standard deviations) for 60 children studied over the same period of time as the tetralogy $\infty$ patients. None of the patients developed an arrhythmia during exercise at catheterisation. $\frac{}{3}$ Subject 6 subsequently developed exercise induced ventricular tachycardia with treadmill testing, as has been reported by James et al. (1976) in patients after operation for Fallot's tetralogy.

The peak right ventricular pressure increased during exercise in all subjects and in only 3 subjects was the pressure during exercise less than the normal maximal value of $48 \mathrm{mmHg}$ (Fig. 1). The peak right ventricle to pulmonary artery pressure gradient increased during exercise in all subjects, and in all but 4 subjects was abnormal during exercise (Fig. 2). There was one very high value in the 'poor repair' group, and 5 of 7 subjects with residual pulmonary stenosis had peak gradients of over $50 \mathrm{mmHg}$ with exercise. There was a strong correlation between the resting and exercise right

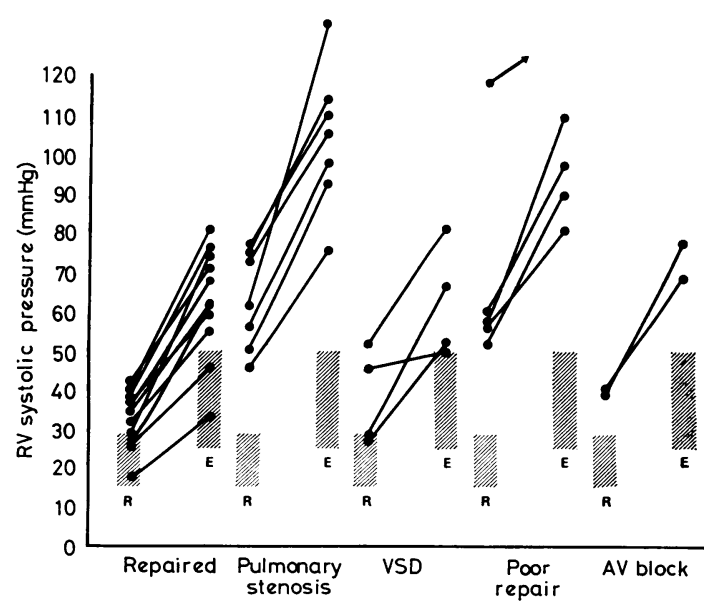

Fig. 1 Peak systolic pressure in the right ventricle at rest $(R)$ and immediately after exercise $(E)$. Normal range is shown by hatched columns. 


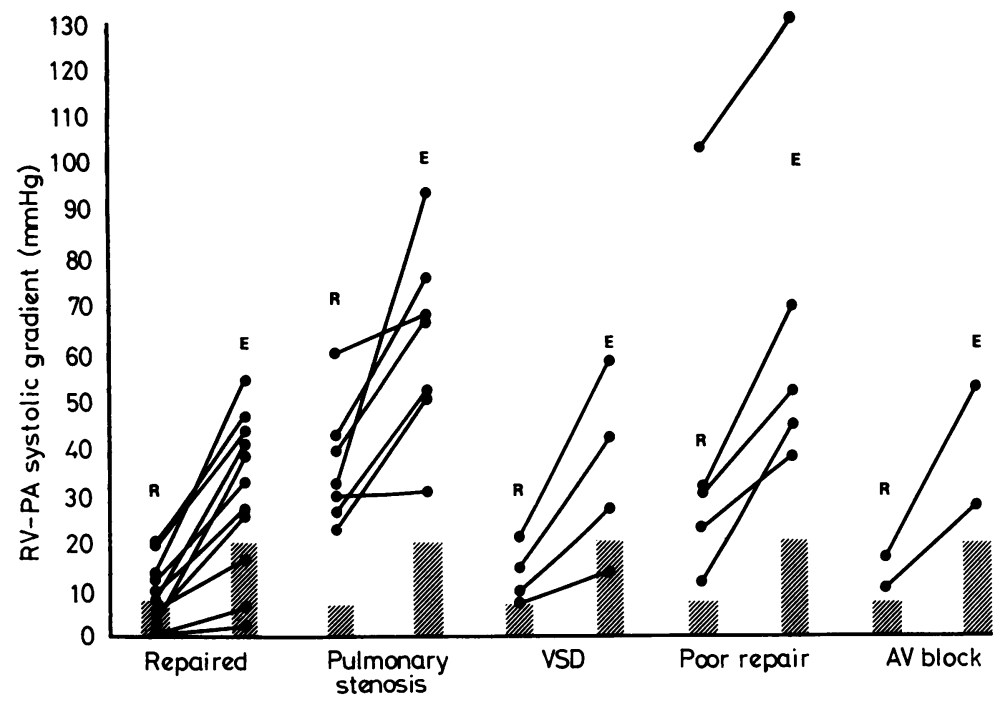

Fig. 2 Peak right ventricular systolic pressure minus peak pulmonary artery systolic pressures at rest $(R)$ and immediately after exercise $(E)$. Normal range (up to $8 \mathrm{mmHg}$ rest and $20 \mathrm{mmHg}$ after exercise) is shown. ventricular systolic pressures and right ventricle to pulmonary artery gradient though there were a few exceptions (2 patients with resting gradients of 2 and $32 \mathrm{mmHg}$ had exercise gradients of 40 and $94 \mathrm{mmHg}$, respectively).

Right ventricular end-diastolic pressure increased abnormally in all 5 subjects in the 'poor repair' group, in both patients with atrioventricular block, and in 3 of the 7 patients with resting gradients over $20 \mathrm{mmHg}$ (Fig. 3). Several other patients had an abnormal right ventricular end-diastolic pressure at rest but did not show any major increases on exercise. There was a low order correlation between the exercise right ventricular end-diastolic pressure and the right ventricular systolic pressure.

Fig. 4 shows the cardiac output at submaximal work loads expressed as the increase in output above the resting value. Eighty-four per cent of the 45 values fell below the mean established for the normal subjects, but only $6(13 \%)$ were more than 2 standard deviations below the mean and these low values occurred in 3 patients. Values above the mean for the normals were observed 7 times, though none was more than 1 standard deviation

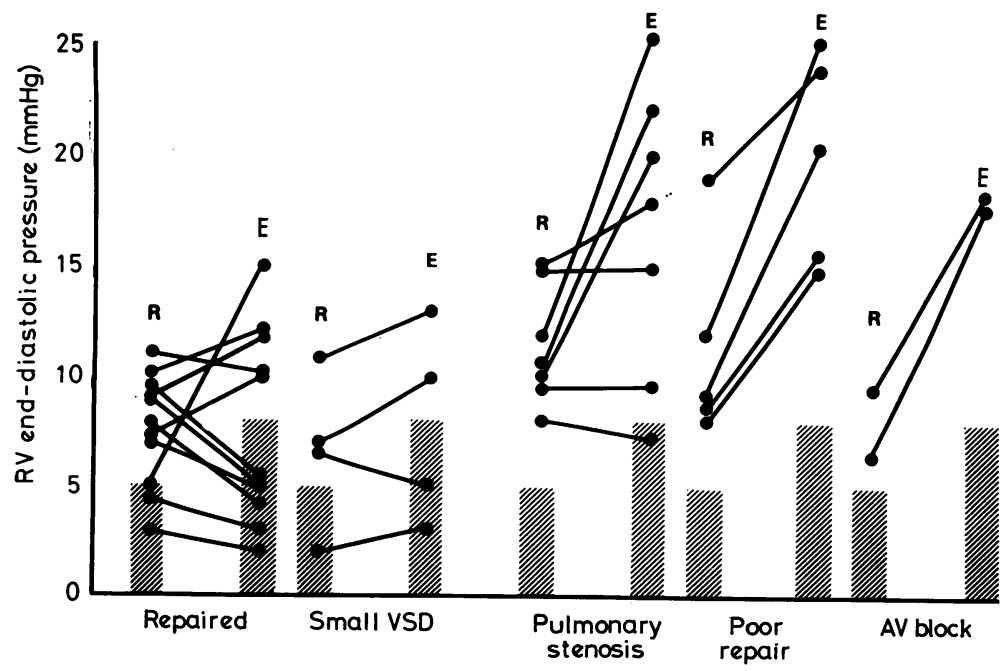

Fig. 3 Right ventricular end-diastolic pressure at rest $(R)$ and after exercise $(E)$. Normal range (up to $5 \mathrm{mmHg}$ at rest and $8 \mathrm{mmHg}$ during or after exercise) is shown. 


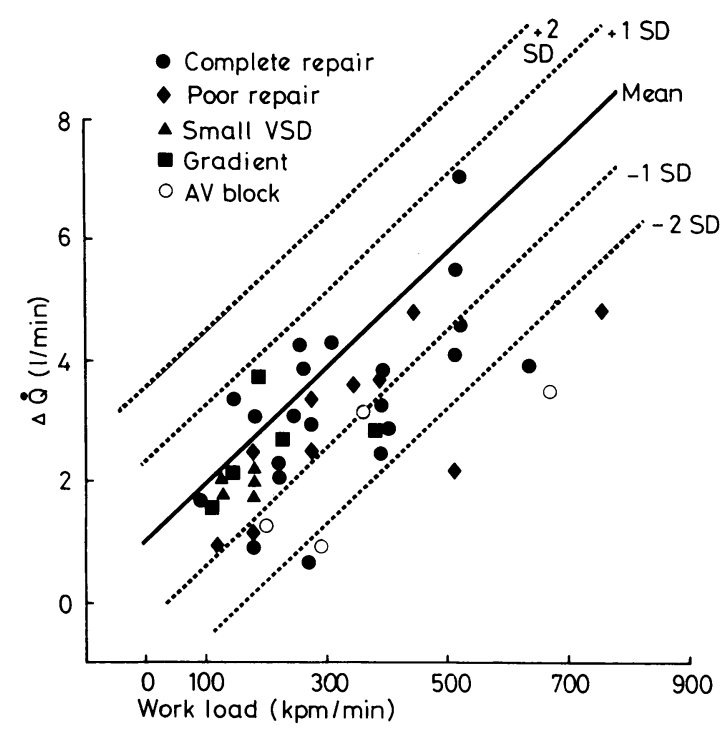

Fig. 4 Cardiac output increase with submaximal exercise $(\triangle \dot{Q})$. Exercise cardiac output minus resting output in litres per minute plotted against work load in kilopond metres per minute. Regression (solid) line is shown for normal subjects with standard deviations (dotted lines).

above the mean. Thus, the cardiac output during submaximal exercise was in the lower half of the normal range in most patients.

Resting cardiac index was below $2.91 / \mathrm{min}$ per $\mathrm{m}^{2}$ in 5 subjects $(21 \%)$ and below the mean of the normal values for this laboratory in 18 subjects $(75 \%)$ (Fig. 5). Maximal exercise cardiac index (measured in 24 patients) was below the normal range in two subjects, the boy with complete atrioventricular block and one patient with a poor repair. However, maximal cardiac index was below

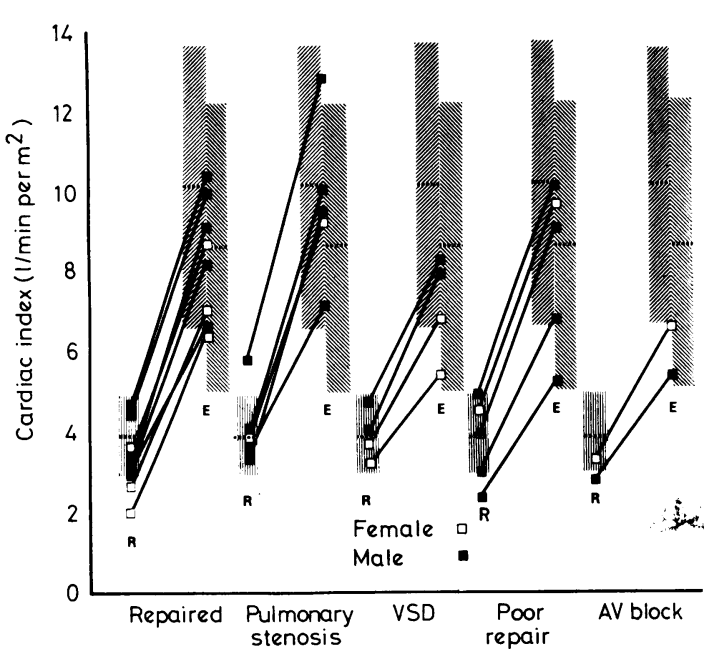

Fig. 5 Cardiac index in litres/minute per $m^{2}$ body surface area at rest and during maximal exercise. Hatched columns indicate the normal ranges which are the same for boys and girls at rest, but different during exercise: during exercise the normal ranges for boys are shown on the left, and the normal ranges for girls on the right; the dotted lines in these ranges indicate the mean values for the normal group.

the mean value for normals in 19 of the 24 subjects exercised maximally (79\%).

During submaximal supine exercise, stroke volume in normal children usually increases about 10 per cent above resting (Cumming, 1972). The response to maximal exercise is variable, with stroke volume either staying the same, decreasing, or occasionally increasing slightly compared with values for submaximal exercise. Fig. 6 shows the resting stroke volume indices, and the highest values observed during exercise. There was an increase in

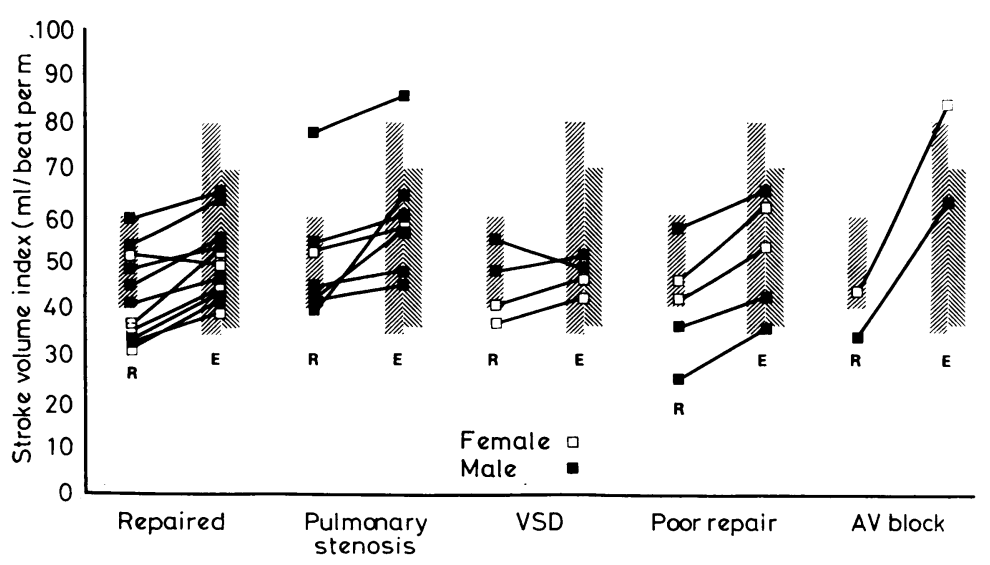

Fig. 6 Stroke volume index in ml beat per $m^{2}$ body surface area at rest $(R)$ and during exercise $(E)$. The normal ranges are shown as in Fig. 5. 


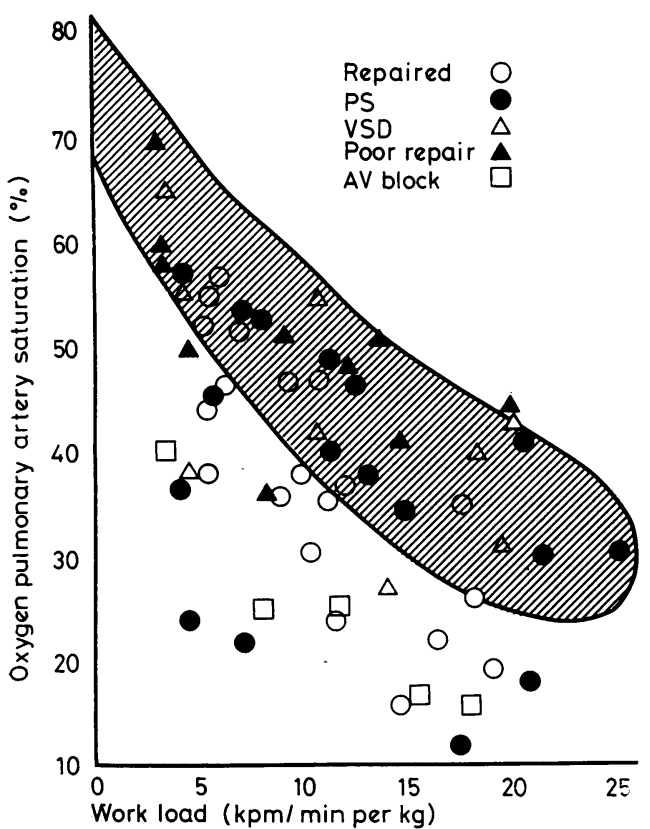

Fig. 7 Percentage oxygen saturation in pulmonary artery blood during exercise plotted against work load in $\mathrm{kpm} / \mathrm{min}$ per $\mathrm{kg}$ body weight. Hatched area shows normal range.

stroke volume index with exercise in all except 2 patients. This increase was greatest in the 2 subjects with heart block.

The percentage oxygen saturation in the pulmonary artery blood during exercise is plotted against the work load per kg body weight in Fig. 7 . There were some subjects in all patient groups with

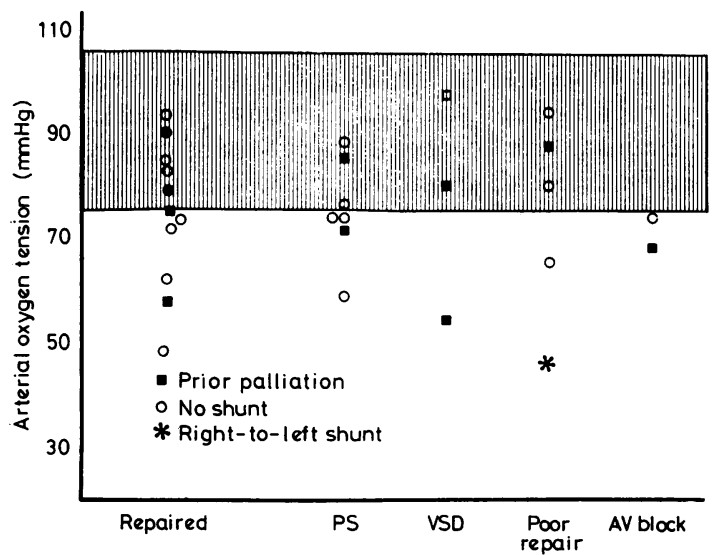

Fig. 8 Brachial artery $\mathrm{Po}_{2}$ during the maximal supine exercise load performed by the subjects. Shaded area shows the normal range in this laboratory. Patients who had previous systemic-to-pulmonary artery anastomoses are shown by . Patient $*$ was the only one with a right-toleft shunt on the indicator dilution curve. values below the normal range, including the 2 patients in group 5 with heart block. Some of the patients with left-to-right shunts had values in the high normal range.

The arterial $\mathrm{Po}_{2}$ values during the maximal exercise performed by each subject are shown in Fig. 8. Relatively low $\mathrm{Po}_{2}$ values were found in some normal subjects during near maximal supine exercise, the lower limit of normal being $75 \mathrm{mmHg}$. (When blood is collected 2 or 3 minutes after exercise, most normal subjects, including those with exercise values of 75 to $80 \mathrm{mmHg}$, have arterial $\mathrm{Po}_{2}$ values in the range of 90 to $110 \mathrm{mmHg}$.) In the postoperative Fallot's tetralogy patients arterial $\mathrm{Po}_{2}$ was below the normal range in 14 of the 28 patients. In 1 subject this was associated with a moderate right-to-left shunt on the indicator dilution curve, but in the other patients no right-toleft shunt was present. In view of the interesting abnormalities in lung function that follow systemicto-pulmonary shunt operations (Alderson et al., 1975), those patients who had had previous shunt operations are indicated in Fig. 8, but their values were no lower than those without previous shunt operations.

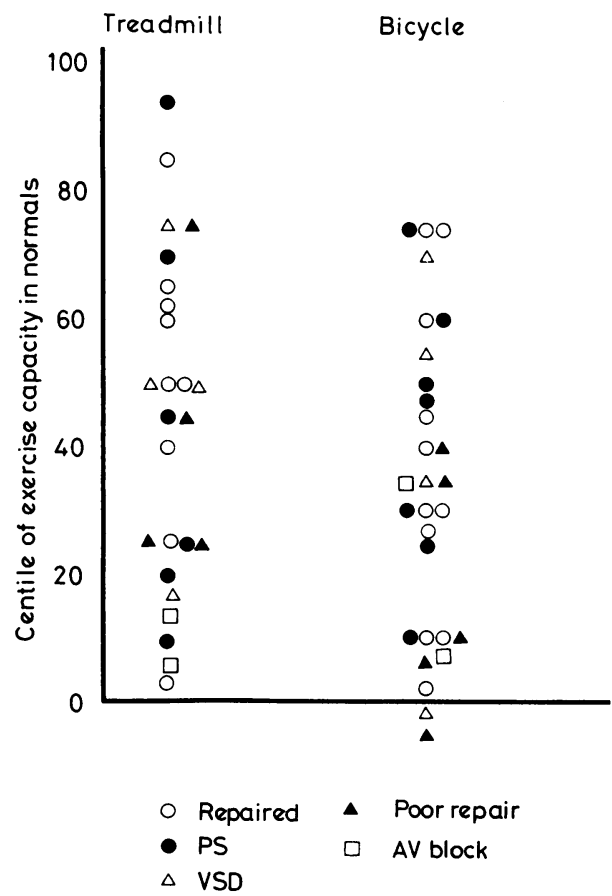

Fig. 9 Exercise capacity on treadmill (endurance time) and upright (maximal work load) bicycle ergometer. Normal centile values were obtained on clinic patients with innocent heart murmurs. 
The endurance times with the Bruce treadmill procedure and the maximal exercise load with the clinical bicycle ergometer test are shown as centiles of the values established for children without heart disease in Fig. 9. For treadmill exercise the mean centile recorded by the postoperative Fallot's tetralogy patients was 45 per cent, excluding the 1 patient who developed ventricular tachycardia with exercise. Of the 25 subjects tested, 52 per cent had values below the 50 th centile, 16 per cent had values approximately on the 50th centile line, and 32 per cent had values above the 50th centile line. The mean maximal heart rate was 189 beats/min (normal mean 202 beats/min).

The maximal work loads completed on the upright bicycle ergometer were above the 50th centile line in 7 subjects (24\%), below the 25th centile line in $9(31 \%)$, including $3(10 \%)$ below the 3 rd centile line, and no subject had a value above the 75th centile line. The mean centile score was 37 per cent. Mean group centile exercise capacities were lowest in the patients with atrioventricular block and in those with a 'poor repair', but there was considerable overlap. The mean maximal exercise heart rate was 183 beats/min (normal mean 196 beats/min).

\section{Discussion}

The systolic pressure increase on withdrawing the catheter from the pulmonary artery to the right ventricle was abrupt and no intermediate zone suggestive of infundibular stenosis was observed. This was in keeping with the right ventricular angiograms which showed wide open outflow tracts in all patients. The pressure changes appeared to be occurring in the area of the pulmonary valve ring, or at the bifurcation of the main pulmonary artery, and while these were the narrowest areas on the angiograms a significant gradient would not have been suspected from viewing the angiograms.

The rise in exercise right ventricular enddiastolic pressures is in agreement with the report of Bristow et al. (1970) and might be the result of the previous right ventricular incision, the pulmonary regurgitation, the increase in right ventricular systolic work, or of myocardial hypertrophy and scarring with reduced compliance. The highest end-diastolic pressures were found in the subjects with the most severe haemodynamic disturbances, but the right ventricular end-diastolic pressures did not correlate with exercise cardiac output or the clinical exercise capacity, or the presence of a pulmonary regurgitant murmur.

Peak systolic pulmonary artery pressures might be abnormally high on the basis of branch narrowings, reduced size or compliance of the major pulmonary arteries, inadequacy of the pulmonary vascular bed, possible old thrombotic occlusions, or increased right ventricular stroke volume because of the pulmonary regurgitation, or combinations of the above causes. At preoperative catheterisation, none of the patients had pulmonary hypertension from previous shunt procedures. There was no correlation between the peak pulmonary artery pressure and the clinical grading of the pulmonary regurgitation murmur or the presence of a systemic-topulmonary shunt.

The submaximal and maximal exercise cardiac indices and stroke volume indices were clustered in the lower part of the normal range. This is a better response than those reported by Epstein $e t$ al. (1973) and by Bjarke (1975). The submaximal exercise cardiac outputs were in the lower part of the normal range because of low stroke volumes. The maximal cardiac outputs were low because of low maximal heart rates. The mean maximal exercise heart rate for the supine exercise at the time of catheterisation was only 164 beats/min, and this low figure is believed to be due to three factors. Maximal exercise heart rates in the supine position are normally 10 beats/min below those for the sitting position in adults and in children (Åstrand and Saltin, 1961; Stenberg et al., 1967; Cumming, 1977b). Secondly, maximal exercise heart rates for upright bicycle and treadmill exercise have been reported to be reduced by 20 beats/min in post-surgical patients with Fallot's tetralogy (Epstein et al., 1973; Bjarke, 1975), though the cause is uncertain. Thirdly, the short duration of the maximal exercise used in this study would be an additional factor reducing the maximal heart rate. At catheterisation the duration of the exercise was purposely kept short as this has been one way of obtaining the co-operation of young children. The subjects pedalled until they could not maintain the cycling speed of $70 \mathrm{rpm}$, and most appeared to have given a true near maximal effort; the only way the duration of exercise could have been increased would have been to reduce the work load used.

A slight fall in arterial oxygen saturation with exercise in postoperative tetralogy patients was reported by Epstein et al. (1973) and in the study of Bjarke (1975) $\mathrm{PaO}_{2}$ fell from 99 to $85 \mathrm{mmHg}$ with upright bicycle exercise. The lower values in the patients in this series may have been caused in part by the supine position and the straining that this type of exercise produces. Ventilation perfusion abnormalities have been well documented in postoperative tetralogy patients (Alderson et al., 1975).

Before any reduction in maximal exercise performances of post-surgical patients can be 
attributed to residual lesions and impaired cardiac function, it is important to exclude non-cardiac factors. Have the patients actually resumed full activity for at least 6 months or longer, or have they held back for one reason or another? Are the patients really being urged to produce maximal efforts in the tests? Is the normal group of subjects roughly comparable with the patients in terms of current physical activity? When comparing the exercise haemodynamic indices or exercise capacity measurements in patients with values in normal subjects, it is important that both groups should have engaged in comparable physical activity. Ideally, both groups should undergo a similar physical training programme 3 or 4 months before a study, and this would include practice sessions with all test procedures. As this was not feasible, the normal values in this study were obtained from a large series of patients who proved to have normal hearts, or nearly normal hearts, when undergoing cardiac evaluation over the same period of time as the postoperative tetralogy patients. The tetralogy patients in this series were all urged gradually to resume normal activities, including full participation in physical education 6 months after operation. The parents were advised to encourage their children to participate normally in all activities while allowing them to seek their own levels of participation rather than to be coached and pushed. Several children, in fact, did take part in demanding sports such as ice-hockey or soccer, but none trained seriously for competitive athletics.

The results of all maximal exercise tests are dependent on motivating the patients to work close to exhaustion, and the skill and determination of exercise technicians is an important factor. All of the subjects in this report finished at least stage 4 of the Bruce test which, if done aerobically, requires an oxygen uptake of $46 \mathrm{ml} / \mathrm{min}$ per $\mathrm{kg}$ (Cumming et al., 1978). While oxygen uptake was not directly measured, there is no reason to believe that the work efficiency or the anaerobic power of these patients was any greater than in normal subjects.

The patients in this series clearly had higher functional capacities than those in the series of Epstein et al. (1973) and Bjarke (1975) ( $\dot{V}_{2} \max$ 25 to $30 \mathrm{ml} / \mathrm{min}$ per $\mathrm{kg}$ ) possibly because the operation was performed at a younger age and the patients had the motivation and opportunity to become normally active. The younger patients of Mocellin et al. (1975) also had cardiac output values closer to normal than those reported by Epstein et al. (1973) and Bjarke (1975). It is of interest that with clinical exercise testing our patients were able to push themselves to a mean maximal heart rate of 189 beats/min compared with approximately 175 beats/min in the studies of Epstein et al. (1973) and Bjarke (1975), and 182 beats/min in the study of James et al. (1976). Maximal heart rates of over 190 beats/min, well within the range of normal for maximal heart rate, were recorded during clinical exercise testing in 15 of the 27 patients (2 patients with atrioventricular block omitted). It would be of value to study systematically the response of postoperative tetralogy patients to physical training regimens, but the results reported here indicate that formal rehabilitation programmes are not necessary for these patients to achieve a reasonable functional status.

James et al. (1976) found that patients operated on at an earlier age (under age 10) had exercise capacities not significantly different from normal subjects, while those operated on at an older age had subnormal exercise capacities when tested by clinic bicycle ergometry, in agreement with the findings of this report. They also studied 4 older subjects who took part in competitive sports, and found that their exercise capacities were also normal, suggesting that the potential for a normal exercise capacity is present if physical activity is encouraged for these patients.

The mean age of the 10 patients studied by Epstein et al. (1973) was 23 years, and of the 18 patients studied by Bjarke (1975) 20 years at operation and 26 years at the time of the postoperative exercise study. The cardiac output response to treadmill exercise in Epstein's series was only slightly below normal, but there was an abnormally low cardiac index at the point when pulmonary artery oxygen saturation fell to 30 per cent. In the study of Bjarke (1975), cardiac outputs during upright bicycle exercise were clustered in the low normal range and 50 per cent of the subjects had values below the normal range in relation to oxygen uptake. In their patients the circulation tended to be hypodynamic in tetralogy patients after operation, even when allowance was made for the reduced maximal exercise capacity and maximal oxygen uptake. In the patients in our series studied during supine exercise, the changes were similar in direction but not in magnitude, so that the exercise cardiac outputs were at the lower end of the normal range but not below. The study of Mocellin et al. (1976) involved 21 children, mean age 12 years, operated on at a mean age of 8.5 years, subjects comparable to those in the present report. Mean maximal exercise heart rate was 196 beats/ min, the same as normals. The mean maximal $\mathrm{Vo}_{2}$, stroke volume, and cardiac output were 83 to 89 per cent of mean normal values (based on height), though information was not provided on the normal range or the method of selection of the normal 
subjects. Presenting our patients' data in the same way and omitting those with a poor repair or atrioventricular block, the mean values for exercise capacity, stroke volume, and cardiac output were also 85 to 90 per cent of the means for normals. The mean $\mathrm{Vo}_{2} \max$ in Mocellin's subjects was determined directly on the bicycle ergometer and was 37 and $34 \mathrm{ml} / \mathrm{min}$ per $\mathrm{kg}$ for boys and girls, respectively, lower than the predicted values based on treadmill performance in our patients. Mocellin et al. indicated that only half of their children took part in school sports, but it is not known whether intense physical activity might be damaging to these children or the only way in which they might achieve a normal functional capacity. All the evidence available suggests that early operation may permit the development of a more normal exercise performance. This may be entirely because of the resumption of normal physical activity during the years of development, but there is also the possibility that cardiac fibrosis, a small left ventricle, and other anatomical abnormalities occur to a greater degree when surgical correction is delayed until late adolescence or adulthood.

\section{Conclusions}

(1) After corrective operations for tetralogy of Fallot there are residual haemodynamic abnormalities during exercise, the most striking being high right ventricular systolic and end-diastolic pressures. The high right ventricular systolic pressure occurs in the absence of any angiographic evidence of outflow tract obstruction.

(2) When the corrective operation was done in childhood (age 5 to 13 years), patients with Fallot's tetralogy had exercise capacities in the low normal range during treadmill, upright bicycle, or supine bicycle exercise.

(3) After corrective operations in childhood, the maximal and submaximal exercise cardiac outputs and stroke volumes fall in the lower part of the normal range, but are usually not below normal. The hypodynamic circulation is partially compensated for by a wider arteriovenous oxygen difference.

(4) Patients with a poor repair or with atrioventricular block (with pacemakers) had only slightly less good exercise performances and cardiac output measurements than those with better anatomical results.

All but one of the patients in this series were operated on by Dr Colin C. Ferguson, Department of Surgery, Children's Hospital of Winnipeg.

\section{References}

Alderson, P. O., Boonvisut, S., McKnight, R. C., and Hartman, A. F., jun (1975). Pulmonary perfusion abnormalities and ventilation perfusion imbalance in children after total repair of tetralogy of Fallot. Circulation, 53, 332-337.

Åstrand, P. O., and Saltin, B. (1961). Maximal oxygen uptake and heart rate in various types of muscular activity. fournal of Applied Physiology, 16, 977-981.

Bjarke, B. (1975). Oxygen uptake and cardiac output during submaximal and maximal exercise in adult subjects with totally corrected tetralogy of Fallot. Acta Medica Scandinavica, 197, 177-186.

Bristow, J. D., Kloster, F. E., Lees, M. H., Menashe, V. D., Griswold, H. E., and Starr, A. (1970). Serial cardiac catheterisations and exercise hemodynamics after correction of tetralogy of Fallot. Circulation, 41, 1057-1066.

Carter, S. A., Bajec, D. F., Yannicelli, E., and Wood, E. H. (1960). Estimation of left to right shunts from arterial dilution curves. Fournal of Laboratory and Clinical Medicine, $55,77-88$.

Cumming, G. R. (1972). Stroke volume during recovery from supine bicycle exercise. Fournal of Applied Physiology, 32, 575-578.

Cumming, G. R. (1977a). Exercise studies in clinical pediatric cardiology (Proceedings of the VIIth International Symposium of Pediatric Work Physiology). In Frontiers of Activity and Child Health, pp. 17-45, ed H. Lavallée and R. Shephard. Éditions du Pélican, Ottawa.

Cumming, G. R. (1977b). Hemodynamics of supine bicycle exercise in 'normal' children. American Heart Fournal, 93, 617-622.

Cumming, G. R. Comparison of maximal supine and upright bicycle exercise in children. In preparation.

Cumming, G. R., Everatt, D., and Hastman, L. (1978). The Bruce treadmill test in children: normal values in a clinic population. American fournal of Cardiology, 41, 69-75.

Epstein, S., Beiser, D., Goldstein, R., Rosing, D., Redwood, D., and Morrow, A. (1973). Hemodynamic abnormalities in response to mild and intense upright exercise following operative correction of an atrial septal defect or tetralogy of Fallot. Circulation, 47, 1065-1075.

Gotsman, M. S. (1966). Hemodynamic and cine-angiographic findings after one stage repair of Fallot's tetralogy. British Heart Fournal, 28, 448-460.

Hetzel, P. S., Swan, H. J. C., Ramirez de Arellano, A. A., and Wood, E. H. (1958). Estimation of cardiac output from the first part of arterial dye dilution curves. fournal of Applied Physiology, 13, 92-96.

James, F. W., Kaplan, S., Schwartz, D. C., Chou, T., Sandker, M. J., and Naylor, V. (1976). Response to exercise in patients after total surgical correction of tetralogy of Fallot. Circulation, 54, 671-679.

Mocellin, R., Bastanier, C., Hofacker, H., and Bühlmeyer, K. (1975). Klinische und funktionelle Ergebinisse bei kindern mit Fallotscher Tetralogie nach Korrekturoperation. Monatsschrift für Kinderheilkunde, 123, 363-365.

Mocellin, R, Bastanier, C., Hofacker, W., and Bühlmeyer, K. (1976). Exercise performance in children and adolescents after surgical repair of tetralogy of Fallot. European fournal of Cardiology, 4, 367-374.

Shah, P. L. and Kidd, L. (1966). Hemodynamic responses to exercise and to isoproterenol following total correction of Fallot's tetralogy. Fournal of Thoracic and Cardiovascular Surgery, 52, 138-145.

Shinebourne, E., Fleming, J., and Hamer, J. (1967). Calibration of indicator dilution curves in man by the dynamic 
method. British Heart fournal, 29, 920-925.

Stenberg, J., Åstrand, P. O., Ekblom, B., Royce, J., and Saltin, B. (1967). Hemodynamic response to work with different muscle groups sitting and supine. Fournal of Applied Physiology, 22, 61-70.
Requests for reprints to Dr Gordon R. Cumming, Section of Cardiology, Health Sciences Children's Centre, 685 Bannatyne Avenue, Winnipeg, Manitoba, Canada R3E 0W1. 